\title{
Series editors' preface
}

This innovative series reflects the breadth and diversity of writing over the last thirty years, and provides critical evaluations of established, emerging and critically neglected writers - mixing the canonical with the unexpected. It explores notions of the contemporary and analyses current and developing modes of representation with a focus on individual writers and their work. The series seeks to reflect both the growing body of academic research in the field, and the increasing prevalence of contemporary American and Canadian fiction on programmes of study in institutions of higher education around the world. Central to the series is a concern that each book should argue a stimulating thesis, rather than provide an introductory survey, and that each contemporary writer will be examined across the trajectory of their literary production. A variety of critical tools and literary and interdisciplinary approaches are encouraged to illuminate the ways in which a particular writer contributes to, and helps readers rethink, the North American literary and cultural landscape in a global context.

Central to debates about the field of contemporary fiction is its role in interrogating ideas of national exceptionalism and transnationalism. This series matches the multivocality of contemporary writing with wide-ranging and detailed analysis. Contributors examine the drama of the nation from the perspectives of writers who are members of established and new immigrant groups, writers who consider themselves on the nation's margins as well as those who chronicle middle America. National labels are the subject of vociferous debate and including American and Canadian writers in the same series is not to flatten the differences between 
them but to acknowledge that literary traditions and tensions are cross-cultural and that North American writers often explore and expose precisely these tensions. The series recognises that situating a writer in a cultural context involves a multiplicity of influences, social and geo-political, artistic and theoretical, and that contemporary fiction defies easy categorisation. For example, it examines writers who invigorate the genres in which they have made their mark alongside writers whose aesthetic goal is to subvert the idea of genre altogether. The challenge of defining the roles of writers and assessing their reception by reading communities is central to the aims of the series.

Overall, Contemporary American and Canadian Writers aims to begin to represent something of the diversity of contemporary writing and seeks to engage students and scholars in stimulating debates about the contemporary and about fiction.

\author{
Nahem Yousaf \\ Sharon Monteith
}

